\title{
Role of Guanosine Kinase in the Utilization of Guanosine for Nucleotide Synthesis in Escherichia coli
}

\author{
By BJARNE HOVE-JENSEN* AND PER NYGAARD \\ Enzyme Division, University Institute of Biological Chemistry B, Solvgade 83, \\ DK-1307 Copenhagen K, Denmark
}

(Received 7 October 1988; revised 20 January 1989; accepted 26 January 1989)

\begin{abstract}
Using purine auxotrophic strains of Escherichia coli with additional genetic lesions in the pathways of interconversion and salvage of purine compounds, we demonstrated the in vivo function of guanosine kinase and inosine kinase. Mutants with increased ability to utilize guanosine were isolated by plating cells on medium with guanosine as the sole purine source. These mutants had altered guanosine kinase activity and the mutations were mapped in the gene encoding guanosine kinase, $g s k$. Some of the mutants had acquired an additional genetic lesion in the purine de novo biosynthetic pathway, namely a $\operatorname{pur} F$, a $\operatorname{pur} L$ or a pur $M$ mutation. A revised map location of the gsk gene is presented and the gene order established as proC-acrA-apt-adkgsk-purE.
\end{abstract}

\section{INTRODUCTION}

A number of purine sources can supply the requirement of purine auxotrophic strains of Escherichia coli. Among these compounds are purine ribonucleosides and deoxyribonucleosides. Adenosine, inosine and guanosine and the corresponding 2'-deoxy compounds can serve as the sole purine source (Nygaard, 1983). The utilization of the purine deoxyribonucleosides is dependent upon the functioning of purine nucleoside phosphorylase, encoded by the deo $D$ gene. Strains that are deoD cannot incorporate exogenous purine deoxyribonucleosides into DNA (Karlström, 1970), nor will pur deoD strains utilize purine deoxyribonucleosides for growth (Hoffmeyer \& Neuhard, 1971).

Several enzymes are responsible for the conversion of purine ribonucleosides to the corresponding ribonucleoside 5'-monophosphates. Inosine, adenosine and guanosine can be phosphorolysed to the corresponding bases and ribose 1-phosphate by purine nucleoside phosphorylase. The bases in turn may be phosphoribosylated to the nucleoside $5^{\prime}$ monophosphates by appropriate phosphoribosyltransferases. Also guanosine and inosine kinase activities have been identified and the gsk gene, encoding guanosine kinase, mapped in E. coli (Jochimsen et al., 1975). Nucleotide synthesis from adenosine proceeds via phosphorolysis as above or through initial deamination to inosine, catalysed by adenosine deaminase (Hoffmeyer \& Neuhard, 1971; Nygaard, 1983; Livshits, 1976). A different pathway has been proposed for converting adenosine to AMP, involving cleavage of adenosine to adenine by an enzyme different from purine nucleoside phosphorylase (Livshits \& Sukhodolets, 1973a). The physiological implications of this enzyme have not been solved, but the enzyme responsible is very likely adenosylhomocysteine nucleosidase. This enzyme has affinity towards adenosine in vitro (Jochimsen, 1979). Relevant auxiliary pathways as well as the de novo purine pathway of $E$. coli are given in Fig. 1. Detailed reviews of the metabolism of purine nucleotides have recently appeared (Nygaard, 1983; Neuhard \& Nygaard, 1987).

Abbreviation: AIR, aminoimidazole ribonucleoside 5'-monophosphate. 


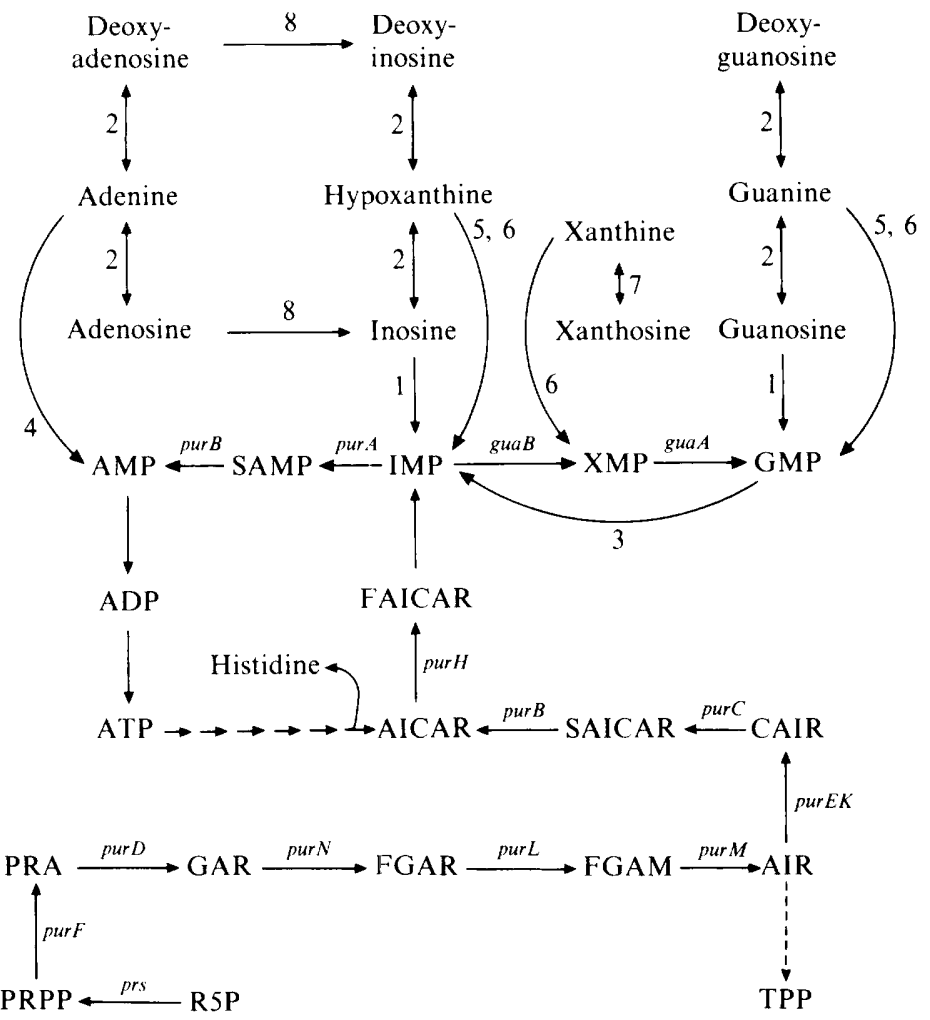

Fig. 1. Auxiliary and de novo pathways of purine nucleotides in E. coli. The abbreviations used for the de novo intermediates: R5P, ribose 5-phosphate; PRPP, phosphoribosylpyrophosphate; PRA, phosphoribosylamine; GAR, glycinamide ribonucleoside 5'-monophosphate; FGAR, formylglycinamide ribonucleoside 5'-monophosphate; FGAM, formylglycinamidine ribonucleoside $5^{\prime}$-monophosphate; AIR, aminoimidazole ribonucleoside 5'-monophosphate; CAIR, carboxaminoimidazole ribonucleoside 5'-monophosphate; SAICAR, succinylaminoimidazolecarboxamide ribonucleoside 5'monophosphate; AICAR, aminoimidazolecarboxamide ribonucleoside 5'-monophosphate; FAICAR, formylaminoimidazolecarboxamide ribonucleoside 5 '-monophosphate; IMP, inosine $5^{\prime}$ monophosphate; XMP, xanthosine 5'-monophosphate; SAMP, succinyl-AMP. The de novo pathway has been extended to include PRPP synthetase, encoded by the prs gene (Hove-Jensen, 1985; HoveJensen $e t$ al., 1986). The individual de novo reactions are indicated by the genes encoding the respective enzymes: purF, glutamine PRPP amidotransferase; $p u r D$, GAR synthase; $p u r N$, GAR formyltransferase; $p$ urL, FGAR amidotransferase; purM, AIR synthase; purEK, AIR carboxylase; purC, SAICAR synthase; purB, adenylosuccinate lyase; $p u r H$, AICAR formyltransferase; purA, adenylosuccinate synthase; guaB, IMP dehydrogenase; guaA, GMP synthetase. In $E$. coli no gene has been assigned to the IMP cyclohydrolase. The broken arrow indicates the reactions leading from AIR to thiamin pyrophosphate (TPP, Newell \& Tucker, 1968). The auxiliary reactions are indicated by numbers: 1 , guanosine kinase (encoded by gsk);2, purine nucleoside phosphorylase (deoD); 3, GMP reductase $(g u a C) ; 4$, adenine phosphoribosyltransferase (apt); 5, hypoxanthine phosphoribosyltransferase (hpt); 6, guanine-xanthine phosphoribosyltransferase $(g p t) ; 7$, xanthosine phosphorylase (xapA); 8, adenosine deaminase $(a d d)$. The reactions leading from ATP to AICAR are part of the histidine biosynthetic pathway. The functioning of this pathway is inhibited by the presence of histidine. The $x a p A$ gene is not expressed unless xanthosine is given as carbon source. Only under these conditions will xanthosine serve as purine source.

Two potent nucleoside transport systems, encoded by the nupC and nupG genes, have been determined genetically in E. coli (Munch-Petersen \& Mygind, 1976; Hansen et al., 1987). The two systems differ slightly in their specificities. Thus, the nup $G$-encoded system is responsible for uptake of all ribonucleosides and deoxyribonucleosides, whereas the nup $C$-encoded system takes up all ribonucleosides and deoxyribonucleosides except guanosine and deoxyguanosine (MunchPetersen \& Mygind, 1983). 
Purine ribonucleoside kinases have been only sparsely described in E. coli (Jochimsen et al., 1975), Salmonella typhimurium (Hoffmeyer \& Neuhard, 1971; Gots et al., 1977) or other organisms (Fink \& Nygaard, 1978). In this study, we have examined the physiological role of guanosine kinase (ATP:guanosine 5'-phosphotransferase, EC 2.7.1.-), by analysing the functioning of the enzyme in vivo. We further present a characterization of mutants with improved utilization of guanosine as a purine source. Among these mutants, we found some that had increased activity of guanosine kinase. Guanosine-utilizing mutants have been previously described. Two types of mutants were isolated in $E$. coli by Livshits \& Sukhodolets $(1973 b)$ : one type was found among rifampin-resistant mutants; the other was isolated by using guanosine as the sole purine source, and the genetic lesion mapped close to the purE gene. Both in E. coli and in $S$. typhimurium guanosine-utilizing mutants with defective phosphoribosylpyrophosphate synthetase have been reported (Hove-Jensen \& Nygaard, 1982; Jochimsen et al., 1985).

\section{METHODS}

Bacterial strains. All the E. coli K12 strains used and their genotypes are listed in Table 1.

Media, cell growth and the preparation of cell extracts. Growth medium was phosphate-buffered AB minimal medium (Clark \& Maaløe, 1967). Broth medium contained, per litre: $10 \mathrm{~g}$ Bactotryptone (Difco), $5 \mathrm{~g}$ yeast extract (Difco), $5 \mathrm{~g} \mathrm{NaCl}, 1 \mathrm{~g}$ glucose. Solid media were prepared by adding 1.5\% (w/v) agar (Difco) to AB or broth ingredients. Growth rates were determined by growing $20 \mathrm{ml}$ cultures in $200 \mathrm{ml}$ flasks with aeration by shaking at $37^{\circ} \mathrm{C}$. Growth was followed as optical density (OD) at $436 \mathrm{~nm}$ in an Eppendorf $1101 \mathrm{M}$ photometer. An OD ${ }_{436}$ of

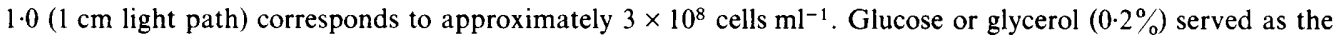
carbon source. When necessary, amino acids were added to $40 \mathrm{mg} \mathrm{l}^{-1}$. Purine bases were added to $15 \mathrm{mg}^{-1}$, ribonucleosides to $30 \mathrm{mg} \mathrm{l}^{-1}$. Nicotinic acid was added to $1 \mathrm{mg} \mathrm{l}^{-1}$. Thiamin $\left(1 \mathrm{mg} \mathrm{l}^{-1}\right)$ was added to all minimal media unless otherwise stated. Tetracycline was used at $5 \mathrm{mg} \mathrm{l}^{-1}$. Cultures for enzyme analysis were grown at $37^{\circ} \mathrm{C}$ with aeration by air bubbling. At an $\mathrm{OD}_{436}$ of approximately 1 the cells were cooled and harvested by centrifugation. Following a wash in $0.9 \%$ saline, the cells were suspended in $50 \mathrm{~mm}$ - Tris/ $\mathrm{HCl}, \mathrm{pH} 7.8$, at 50 times the original cell density. After homogenization by sonication and removal of debris by centrifugation, the cell extract was desalted by passage through a small column of Sephadex G25, equilibrated with $50 \mathrm{mM}-\mathrm{Tris} / \mathrm{HCl}$, pH $7 \cdot 8$.

Guanosine kinase assay. Specific activity is given as $\mathrm{nmol} \mathrm{min}^{-1}$ (mg protein) $)^{-1}$. Protein content was determined by the Lowry method, with bovine serum albumin as the standard. Guanosine kinase activity was determined by a modification of the procedure described by Jochimsen et al. (1975). The assay contained, in a final volume of $0.1 \mathrm{ml}: 70 \mathrm{~mm}$-Tris $/ \mathrm{HCl}$, pH $7.8 ; 35 \mathrm{~mm}-\mathrm{KCl} ; 35 \mathrm{~mm}-\mathrm{MgCl}_{2} ; 1 \mathrm{~mm}-\mathrm{ATP} ; 0.5 \mathrm{~mm}\left(18.5 \mathrm{GBq} \mathrm{mol}^{-1}\right)$ $\left[\mathrm{U}-{ }^{14} \mathrm{C}\right]$ guanosine; $10 \mathrm{mM}$-phosphoenolpyruvate; $1 \mu \mathrm{g}$ pyruvate kinase; and guanosine kinase activity $(0 \cdot 2-1 \cdot 0$ $\mathrm{nmol} \mathrm{min}^{-1}$ ). Samples were removed at appropriate intervals and processed as described by Jochimsen et al. (1975).

Incorporation of $\left[{ }^{14} \mathrm{C}\right.$ guanosine into nucleic acids. At an $\mathrm{OD}_{436}$ of 0.05 , cells growing exponentially at $37^{\circ} \mathrm{C}$ were supplemented with $10 \mu \mathrm{M}-\left(40 \mathrm{GBq} \mathrm{mol}{ }^{-1}\right)\left[8-{ }^{14} \mathrm{C}\right]$ guanosine and allowed to incorporate radioactivity until an $\mathrm{OD}_{436}$ of 1 was reached. Then the cells were treated with $0 \cdot 5 \mathrm{M}$-trichloroacetic acid and the radioactivity incorporated into nucleic acids was determined as acid-insoluble material.

Determination of 5-aminoimidazole ribonucleoside 5'-monophosphate $(A I R)$. The procedure of Bratton \& Marshall (1939) was employed. In this procedure AIR, excreted from the cells as the ribonucleoside, is converted to a coloured diazo compound, with an absorption maximum at $500 \mathrm{~nm}$.

Ribonucleoside triphosphate pool determinations. Cells were grown in a Tris-buffered medium containing $0.3 \mathrm{~mm}$ $P_{\mathrm{i}}$ (Jensen et al., 1979). After several generations of exponential growth, carrier-free ${ }^{32} \mathrm{P}_{\mathrm{i}}$ (Forsøgscenter Risø, Denmark) was added at $1.22 \mathrm{TBq} \mathrm{mol}^{-1}$. Following an additional two generations of growth, the nucleotides were extracted by addition of $\mathrm{HCOOH}$ to a final concentration of $0.33 \mathrm{M}$. Nucleotides were separated by twodimensional thin-layer chromatography as described by Neuhard et al. (1965).

Mutagenization. Cells growing exponentially in supplemented minimal medium were harvested, washed and resuspended in unsupplemented medium, placed under a UV lamp, irradiated to approximately $0 \cdot 1 \%$ survival and grown overnight in minimal medium for phenotypic expression. Alternatively, the cells were infected with bacteriophage Mucts62 by placing droplets of a phage lysate onto a lawn of recipient cells in soft agar. Cells from the infected area were cut out of the agar, inoculated in broth medium and grown overnight for phenotypic expression.

Transduction. Pl vir lysates were prepared by the soft agar overlay technique and transduction was performed as described by Lennox (1955). Genetic markers were scored as follows: the acr $A$ marker was scored on broth plates supplemented with acriflavine (Nakamura et al., 1975); adk is a temperature-sensitive marker (Ray et al., 1970); apt was scored on plates with adenine serving as purine source (Jochimsen et al., 1975). 
Table 1. Bacterial strains used

Strain

$\mathrm{HOl}$

$\mathrm{HO} 3$

$\mathrm{HO} 4$

HO20

$\mathrm{S} \varnothing 1172$

AB2849

HO9

HO48

HO54

HO55

$\mathrm{HO} 105$

HO419

N43

N2485

ORF4/KL251

PA3306

SØ003

SØ198

$\mathrm{S} \varnothing 199$

$\mathrm{Sø} 236$

Sø312

$\mathrm{S} \varnothing 405$

SØ408

SØ445

$\mathrm{S} \varnothing 446$

SØ490

$\mathrm{S} \varnothing 1023$

SØ1098

SØ1628

$\mathrm{S} \varnothing 1704$

$\mathrm{S} \varnothing 1726$
Genotype*

met $B$ rpsL relA spoT $\sup F \operatorname{lam} B$ purE deoD apt purL gsk-10

met $B$ rpsL relA spoT supF lamB purE deoD apt gsk-3

metB rpsL relA spoT supF lamB purE deo $D$ apt purF gsk-4

metB rps $L$ relA spoT supF lamB purE deoD apt purM : : Mucts62 gsk-9 metB rpsL relA spoT supF lamB purE deo $D$ apt lon prs-1 gsk-2

aroC

met $B$ rps $L$ relA spoT supF lamB purE deoD apt purM : : $\triangle$ Mucts62 gsk-9

met $B$ rps $L$ relA spoT supF lamB purE deoD apt lac ZY

met $B$ rpsL relA spoT supF lamB purE deoD apt lon prs-I gsk-2 proC

metB rpsL relA spoT supF lamB purE deo $D$ apt proC

nadB $\arg H$ thi

met $B$ rps $L$ relA spoT supF lamB

$z b b-2419:: \operatorname{Tn} 10 \ddagger$

ara lac galK malA xyl mil rpsL acrAl $a d k-2$ lac

lac $^{+}$purE $E^{+} a p t^{+} /$thi metE trpE purE proC leu $\operatorname{rec} A$ lacZ

purL $L$ nad $B \arg H$ thi

metB rpsL relA spoT supF $\operatorname{lam} B$

metB rpsL relA spoT supF lamB guaA

met $B$ rpsL relA spoT supF lamB purE met $B$ rpsL relA spoT supF lamB guaA thy $A$ deoD

met $B$ rpsL relA spoT supF lamB purE deoD

met $B$ rps $L$ relA spoT supF $\operatorname{lam} B$ purB add deo $D$

metB rpsL relA spoT supF lamB upp

metB rpsL relA spoT supF lamB purE deo $D$ gsk-1

metB rps $L$ relA spoT supF lamB purE deoD apt

met $B$ rpsL relA spoT $\sup F \operatorname{lam} B$ guaA thy $A$ deoD deoB

nupG:: $\operatorname{Tn} 10$ thi relA

met $B$ rps $L$ relA spoT supF lamB deoD guaA

met $B$ rps $L$ relA spoT supF $\operatorname{lam} B$ deo $D$ gua $A$ nup $G:: \operatorname{Tn} 10$

$a d k-2$ lac $z b b-2419:: \operatorname{Tn} 10$

met $B$ rps $L$ relA spoT $\sup F$ lam $B$ purE

deoD adk-2 zbb-2419::Tn 10
Source/construction/application

This work, SØ446, UV mutagenesis

This work, Sø446, UV mutagenesis

This work, SØ446, UV mutagenesis

This work, Sø446, Mu mutagenesis

From Sø446, UV mutagenesis (Hove-Jensen \& Nygaard, 1982)

A. J. Pittard, through CGSC $\dagger$

From $\mathrm{HO} 20$ by plating at $42{ }^{\circ} \mathrm{C}$

SØ446, Lac ${ }^{-}$(Smith \& Sadler, 1971)

Hove-Jensen (1983)

$\mathrm{P} 1(\mathrm{HO} 54) \times \mathrm{HO} 48, \mathrm{Lac}^{+}$

P1(SØ003) $\times$ PA3306, Pur $^{+}$

This work, Tn 10 insertion near gsk

Nakamura et al. (1975), via CGSC +

Nakamura et al. (1975)

K. B. Low, through CGSC $†$

Lavallé, through $\mathrm{CGSC}^{\dagger}$

Defined wild-type strain, derivative of

E. coli K-12 strain W6 (Bachmann, 1972)

From Sø003, UV mutagenesis and

penicillin counterselection

Jochimsen et al. (1975)

From SØ198, K. Hammer (unpublished data)

Jochimsen et al. (1975)

Jochimsen et al. (1975)

Hammer-Jespersen \& Munch-Petersen (1973)

Jochimsen et al. (1975)

Parental strain for mutagenization

(Jochimsen et al., 1975)

From Sø236, low thymine requiring

B. Mygind (unpublished data)

P1(Sø003) $\times$ Sø236, Thy ${ }^{+}$

$\mathrm{Pl}(\mathrm{S} \varnothing 1023) \times \mathrm{S} \varnothing 1098$, Tet $^{\mathrm{R}}$

$\mathrm{P} 1(\mathrm{HO} 419) \times \mathrm{N} 2485, \mathrm{Tet}^{\mathrm{R}}$

$\mathrm{P} 1(\mathrm{~S} \varnothing 1704) \times \mathrm{S} \varnothing 445, \mathrm{Tet}^{\mathrm{R}}$

* All the strains are $\mathrm{F}^{-}$strains, except ORF4/KL251, which is an $\mathrm{F}^{\prime}$ strain, and AB2849 $\left(\mathrm{F}^{+}\right)$.

$\dagger$ Obtained through the Coli Genetic Stock Center (CGSC).

$\ddagger$ Nomenclature of $\mathrm{Tn} 10$ insertions follows the rules of Chumley et al. (1979).

Sexduction. Equal numbers of exponentially growing donor and recipient cells in minimal medium were mixed for $1 \mathrm{~h}$ at $37^{\circ} \mathrm{C}$ and diluted samples plated on selective medium. Streptomycin $\left(200 \mathrm{mg}^{-1}\right)$ was used for counterselection. 
Isolation of a Tn10 insertion near the gsk gene. A bacteriophage P1 lysate was grown on the pool of randomly inserted $\mathrm{Tn} 10$ transposons [transposable genetic element coding for tetracycline resistance $\left(\mathrm{Tet}^{\mathrm{R}}\right)$ ] previously described (Hove-Jensen, 1983). This lysate was used to infect strain SØ199 ( $p u r E$ ) with subsequent selection for Pur $^{+}$Tet $^{\mathrm{R}}$. Among a number of independent Tn 10 insertions obtained and mapped, $z b b \cdot 2419:: \operatorname{Tn} 10$ (HO419) was used in this work.

Isolation of mutants able to utilize guanosine as sole purine source. The strain SØ446 was submitted to UV irradiation or bacteriophage $\mathrm{Mu}$ treatment as described above. Following phenotypic expression, $10^{8}$ cells were plated on glucose minimal medium with guanosine as the sole source of purine. Colonies were purified on the same medium; pur $^{+}$and $d e o D^{+}$revertants were discarded.

Chemicals. All chemicals were commercially available and used without further treatment. [U-14 C]Guanosine and $\left[8-{ }^{14} \mathrm{C}\right]$ guanosine were obtained from Amersham. Phosphoenolpyruvate and pyruvate kinase were from Boehringer Mannheim.

\section{RESULTS}

In vivo evidence for guanosine and inosine kinase activities

The guanine requirement of E. coligua strains can be fulfilled not only by guanine, but also by guanosine. This is also true if purine nucleoside phosphorylase (encoded by deoD) is nonfunctional. As shown in Table 2, strain $\mathrm{S} \varnothing 490$ (guaA deoD) grows almost normally with guanosine serving as source of guanine nucleotides, and its purine ribonucleoside triphosphate pools are almost normal. These results indicate that a pathway different from that involving purine nucleoside phosphorylase for the conversion of guanosine to GMP exists.

To demonstrate inosine utilization, we used a strain defective in inosine $5^{\prime}$-monophosphate synthesis (Fig. 1), SØ312 ( purE deoD), which can be supplied by hypoxanthine or by inosine as shown in Table 2 . However, inosine only poorly fulfils the requirement. If, instead, a strain defective in inosine 5'-monophosphate synthesis and also defective in AMP synthesis (Fig. 1), $\mathrm{S} \varnothing 405$ ( $\operatorname{pur} B$ deo $D$ ) is used, inosine satisfies quite well the need for guanine nucleotides when adenine serves as adenine nucleotide source. Thus, there are only minor differences in the growth rate or in the pools of ATP and GTP, whether the strain is grown with hypoxanthine or inosine to supply the guanine nucleotides. In these experiments, histidine was added to prevent adenine from being converted to guanine nucleotides through the histidine pathway (Fig. 1). The results clearly demonstrate that pathways different from phosphorolysis of guanosine and inosine exist. These pathways depend on guanosine and inosine kinase activities.

\section{Guanosine transport}

To determine whether the guanosine transport system (nupG) was a growth-limiting factor in the utilization of guanosine, we compared the growth of the two strains $\$ \varnothing 1098$ (gua A deoD) and $\mathrm{S} \oslash 1628$ (guaA deoD nupG). Although the transport of guanosine was reduced in the nupG strain

\section{Table 2. In vivo evidence for guanosine and inosine kinase activities of E. coli}

Growth rates and ribonucleotide pools were determined as described in Methods. Values showed less than $10 \%$ variation in duplicate experiments.

\begin{tabular}{|c|c|c|c|c|c|}
\hline \multirow[b]{2}{*}{ Strain } & \multirow[b]{2}{*}{ Genotype } & \multirow{2}{*}{$\begin{array}{l}\text { Addition } \\
\text { to medium }\end{array}$} & \multirow{2}{*}{$\begin{array}{c}\text { Doubling } \\
\text { time } \\
(\min )\end{array}$} & \multicolumn{2}{|c|}{$\begin{array}{c}\text { Nucleotide pool size } \\
{[\text { nmol (mg dry weight })^{-1}}\end{array}$} \\
\hline & & & & ATP & GTP \\
\hline \multirow[t]{2}{*}{$\mathrm{S} \varnothing 490$} & guaA deo $D$ & Guanine & 58 & $3 \cdot 2$ & $2 \cdot 3$ \\
\hline & & Guanosine & 68 & $3 \cdot 0$ & $1 \cdot 2$ \\
\hline \multirow[t]{2}{*}{ Sø312 } & purE deoD & Hypoxanthine & 46 & $6 \cdot 0$ & $2 \cdot 9$ \\
\hline & & Inosine & 200 & $5 \cdot 7$ & $0 \cdot 7$ \\
\hline \multirow[t]{2}{*}{ Sø405 } & purB deo $D^{*}$ & Adenine, hypoxanthine, histidine & 56 & $8 \cdot 5$ & $1 \cdot 8$ \\
\hline & & Adenine, inosine, histidine & 74 & 8.9 & $1 \cdot 2$ \\
\hline
\end{tabular}

* This strain cannot grow with adenine as the sole purine source. 
Table 3. Growth rates of guanosine-utilizing mutants on different purine sources

Growth medium was AB glucose supplemented with thiamin and the indicated purine source. Values indicate doubling time in $\mathrm{min}$.

\begin{tabular}{|c|c|c|c|c|}
\hline \multirow[b]{2}{*}{ Strain } & \multicolumn{4}{|c|}{ Purine source } \\
\hline & Guanosine & Inosine & Guanine & Hypoxanthine \\
\hline $\mathrm{S} \varnothing 446$ & $>600$ & 220 & $>250^{*}$ & 47 \\
\hline $\mathrm{HOl}$ & 78 & 175 & 48 & 47 \\
\hline HO3 & 111 & 99 & 196 & 44 \\
\hline $\mathrm{HO} 4$ & 56 & 137 & 52 & 43 \\
\hline $\mathrm{HO} 9 \dagger$ & 86 & 100 & 60 & 44 \\
\hline SØ1172 & 58 & 89 & $>600$ & 82 \\
\hline
\end{tabular}

\section{Table 4. Guanosine kinase activity and guanosine incorporation in guanosine-utilizing mutants}

Guanosine kinase activity was determined at the temperature indicated by the procedure described in Methods. Incorporation of guanosine into acid-insoluble material was performed as described in Methods.

\begin{tabular}{|c|c|c|c|}
\hline \multirow[b]{2}{*}{ Strain } & \multicolumn{2}{|c|}{$\begin{array}{l}\text { Guanosine kinase activity } \\
{\left[\text { nmol } \min ^{-1}(\text { mg protein })^{-1}\right]}\end{array}$} & \multirow{2}{*}{$\begin{array}{l}\text { Guanosine incorporation } \\
\left.\text { [nmol (mg dry weight })^{-1}\right]\end{array}$} \\
\hline & $37^{\circ} \mathrm{C}$ & $42{ }^{\circ} \mathrm{C}$ & \\
\hline SØ446 gsk+ & $5 \cdot 0$ & $0 \cdot 4$ & 10 \\
\hline $\mathrm{HOl}$ gsk-10 & $5 \cdot 0$ & $2 \cdot 3$ & 125 \\
\hline HO3 gsk-3 & $6 \cdot 8$ & $8 \cdot 6$ & 135 \\
\hline HO4 gsk-4 & 6.6 & 6.9 & 130 \\
\hline HO9 gsk-9 & $8 \cdot 5$ & $8 \cdot 3$ & 105 \\
\hline Sø1172 gsk-2 & 5.7 & 2.9 & 60 \\
\hline
\end{tabular}

as compared to the nup $G^{+}$strain (data not shown), there was no difference in growth rate between the two strains, when the guanosine concentration was varied from 7 to $100 \mu \mathrm{M}$.

\section{Isolation and characterization of mutants with improved utilization of guanosine for nucleotide synthesis}

The utilization of purine ribonucleosides is not very efficient by purE deoD strains of E. coli. Specifically, the utilization of guanosine is very poor. Besides guanosine kinase, the utilization of guanosine by $p u r E$ deo $D$ strains requires the participation of yet another enzyme, GMP reductase (Fig. 1). Although guanosine kinase and GMP reductase can be detected in extracts of purE deo $D$ strains, growth does not occur with guanosine. Assuming that the limiting step under these conditions is the phosphorylation of guanosine, it should be possible to isolate mutants with increased guanosine kinase activity by plating mutagenized pur deoD cells on medium with guanosine serving as sole purine source as described in Methods. From this selection, the following mutants were isolated: $\mathrm{HO}, \mathrm{HO} 3, \mathrm{HO} 4, \mathrm{HO} 20$ and $\mathrm{S} \varnothing 1172$ (Table 1). The growth rates of the guanosine-utilizing mutants supplemented with different purine sources were determined (Table 3). The results indicate that (i) the growth of HO1, HO4 and HO9 is improved not only on guanosine, but also on guanine, a compound that is metabolized without the participation of guanosine kinase, and (ii) growth on inosine is also increased although not to the same extent as on guanosine for strains $\mathrm{HO} 1$ and $\mathrm{HO} 4, \mathrm{HO}$ and $\mathrm{S} \varnothing 1172$ (Table 3). Inosine is metabolized via guanosine kinase.

The mutants were assayed for guanosine kinase, and all had altered guanosine kinase activity (Table 4). Although at $37^{\circ} \mathrm{C}$ there was either no difference or only minor differences between the parent and the mutants, when the enzyme was assayed at $42^{\circ} \mathrm{C}$ the mutants showed a 6- to 
Table 5. Genetic characterization of guanosine-utilizing mutants with secondary purine blocks

Pl transductions were performed as described in Methods, on medium containing glucose and the indicated supplements.

\begin{tabular}{|c|c|c|c|c|c|c|}
\hline $\begin{array}{c}\text { Expt } \\
\text { no. }\end{array}$ & Recipient strain & Donor strain & $\begin{array}{l}\text { Selected } \\
\text { marker }\end{array}$ & $\begin{array}{l}\text { Scored } \\
\text { marker }\end{array}$ & Supplement(s) & $\begin{array}{l}\text { Co-transduction } \\
\text { frequency } \dagger\end{array}$ \\
\hline 1 & $\mathrm{HO}(\operatorname{purL}) / \mathrm{F} 254^{*}$ & HOl05 (nadB) & Pur $^{+}$ & $\mathrm{Nad}$ & Nicotinate & $0 \cdot 11(318)$ \\
\hline 2 & $\mathrm{AB} 2849(\operatorname{aroc})$ & HO4 (purF) & $\mathrm{Aro}^{+}$ & Pur & $\begin{array}{l}\text { Hypoxanthine } \\
\text { and thiamin }\end{array}$ & $0.41(370)$ \\
\hline 3 & HO9 (purM) & $\mathrm{S} \emptyset 408(u p p)$ & $\begin{array}{c}\text { Thiamin } \\
\text { independence }\end{array}$ & Upp $\ddagger$ & Hypoxanthine & $0.95(60)$ \\
\hline
\end{tabular}

\footnotetext{
* The episome was transferred from ORF4/KL251 as described in Methods, by selection for apt $t^{+}$on plates with adenine as the purine source.

$\dagger$ The number of transductants examined is given in parenthesis.

$\ddagger$ The Upp phenotype was scored on plates containing 5-fluorouracil $\left(2.5 \mathrm{mg}^{-1}\right)$. Cells that are upp are resistant, whereas $u p p^{+}$cells are sensitive to 5-fluorouracil.
}

22 -fold increase in specific activity. We also determined the incorporation of guanosine into nucleic acids at $37^{\circ} \mathrm{C}$, and found that the mutants had a 6- to 14-fold increase in incorporation (Table 4). From the enzyme and incorporation data we conclude that the mutants have alterations in the gene specifying guanosine kinase. These mutations result in enzymes that function more efficiently in vivo, and in vitro they appear more heat-stable.

\section{Genetic mapping of the mutations causing altered guanosine kinase activity}

To demonstrate that the mutations causing the alterations in guanosine kinase mapped in the $g s k$ gene we isolated a Tn 10 insertion $(z b b-2419:: \operatorname{Tn} 10)$ between $g s k$ and pur $E$, which are closely linked markers (Jochimsen et al., 1975). The $z b b-2419:: \mathrm{Tn} 10$ allele was then transduced into strain HO3 (purE gsk-3), resulting in a strain with the genotype purE gsk-3 zbb-2419:: Tn 10 . The presence of an altered guanosine kinase was confirmed by assay. A PI lysate was then grown on this purE gsk-3 zbb-2419::Tn10 strain and used to transduce strain SØ445 ( $p u r E$ deoD gsk-I) to tetracycline resistance. Of the 61 transductants analysed, $31 \%$ were able to use guanosine for GMP synthesis, indicating acquisition of a functional gsk gene. Moreover, all these transductants were able to use guanosine as sole purine source, indicating acquisition of the altered guanosine kinase. This was confirmed by assay of the enzyme in some of the transductants. Identical results were obtained for the $g s k-2$ and $g s k-9$ alleles. We therefore conclude that the lesions causing the altered guanosine kinases are, indeed, alleles of the gsk gene.

\section{Mutants with secondary blocks}

While working with the mutants described above, we noticed that the strains $\mathrm{HO} 1, \mathrm{HO} 4$ and HO9 could not be transduced to $\mathrm{Pur}^{+}$by P1 transduction, indicating that the mutants in some way had become double purine auxotrophs. This was confirmed by introducing the episome F254 ( $\left.p u r E^{+}\right)$into the strains. The purine lesions of strains HO1, HO4 and HO9 were characterized by identifying the purine pathway intermediates that the strains accumulated during purine starvation and by genetic mapping of the lesions. None of the mutants accumulated AIR as did the parental purE strain, suggesting mutations in genes specifying the purine enzymes catalysing the early steps of the pathway. All three strains accumulated phosphoribosyl pyrophosphate, but $\mathrm{HO} 4$ did so to a much greater extent than $\mathrm{HO} 1$ and $\mathrm{HO}$, characteristic of purF strains (Jensen et al., 1979). Strain HOl accumulated formylglycinamide ribonucleoside 5'-monophosphate and $\mathrm{HO} 9$ formylglycinamidine ribonucleoside 5 '-monophosphate (cf. Fig. 1), determined by the procedure of Houlberg et al. (1983). These results indicate that $\mathrm{HOl}$ is defective in purL, $\mathrm{HO} 4$ in purF and $\mathrm{HO} 9$ in purM.

The secondary purine lesions in strains $\mathrm{HO} 1, \mathrm{HO} 4$ and $\mathrm{HO} 9$ were mapped by cotransduction with appropriate markers as shown in Table 5 . The data indicate a location of the pur marker in strain $\mathrm{HOl}$ close to $\operatorname{nadB}$, consistent with $\operatorname{purL}$ (experiment no. 1). In strain HO4 the purine 

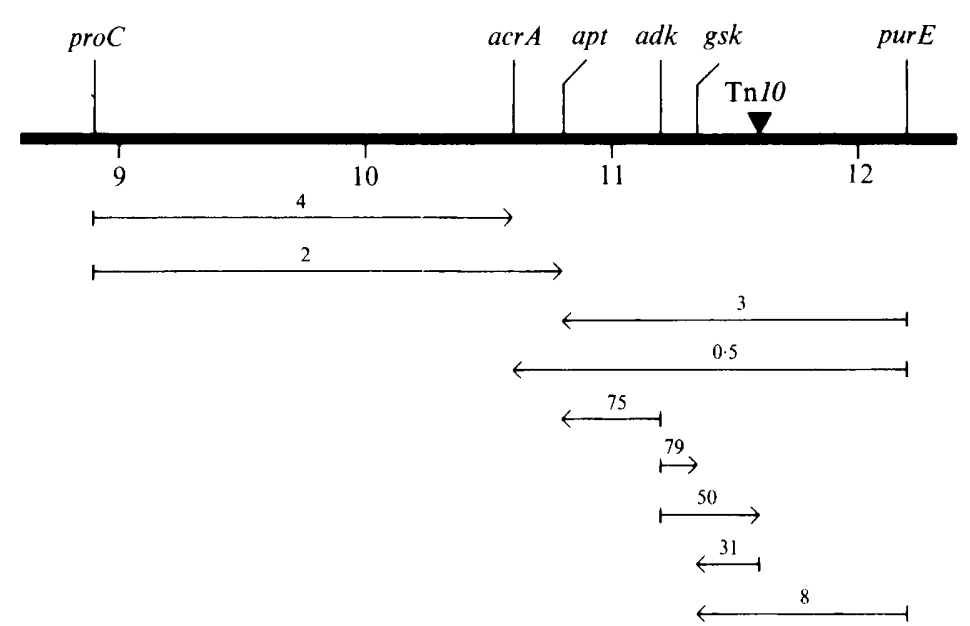

Fig. 2. Map of the proC-purE region of the $E$. coli chromosome. The bar indicates the chromosome. Numbers below the bar are map units in min (Bachmann, 1983). Tn 10 indicates the $z b b-2419:: \operatorname{Tn} 10$ allele. Values above the arrows are percentage co-transduction frequencies based on the data from Table 6 and previously published data (Jochimsen et al., 1975). Arrowheads point towards the unselected markers.

marker was closely linked to aroC, indicative of purF (experiment no. 2, Table 5). Finally the secondary pur marker in strain $\mathrm{HO} 9$ was shown to be purM. Strain HO9 required thiamin for growth (Fig. 1). By selection in transduction for thiamin independence, recombinants that had lost the secondary pur lesion were obtained. The data given in Table 5 (experiment no. 3) revealed that the mutation is very closely linked with upp, as is purM. It appears that the selection of guanosine-utilizing mutants has given rise to double mutants $\mathrm{HO1}$ ( purL gsk-10), HO4 (purF gsk-4), HO9 (purM gsk-9), and also SØ1172 (prs gsk-2). The latter strain has been previously characterized with respect to the defective phosphoribosylpyrophosphate synthetase, encoded by prs (Hove-Jensen \& Nygaard, 1982; Hove-Jensen, 1983).

\section{Genetic mapping of gsk}

While studying the genetics of the gsk mutants, we found that the $g s k$ gene was incorrectly placed on the current linkage map (Jochimsen et al., 1975; Bachmann, 1983). Although we confirmed the linkage of $g s k$ and purE, we noticed that $g s k$ was located counter-clockwise of purE rather than clockwise. The previous clockwise assignment was based on two-factor crosses and on complementation data using various F-episomes. We have performed a more detailed genetic analysis of the proC-purE region including the markers $a c r A$, $a d k$, apt and $z b b$ 2419:: $\operatorname{Tn} 10$. The results obtained from three-factor crosses are given in Table 6 and the gene order found is shown in Fig. 2.

\section{DISCUSSION}

Guanosine can be converted to GMP by either of two pathways in $E$. coli: (i) phosphorolysis to guanine (and ribose 1-phosphate) followed by phosphoribosylation of the guanine moiety, or (ii) direct phosphorylation (Fig. 1). Both pathways appear to operate in wild-type E. coli cells when guanosine is taken up from the culture medium and metabolized (Jensen, 1978). It is not known by which pathway the guanosine nucleotides degraded inside the cells are salvaged. The various nucleotidases, most of which are ectoenzymes, degrade nucleoside monophosphates to the nucleosides. Recently an enzyme that degrades dGTP and GTP to deoxyguanosine and guanosine, respectively, has been purified and studied (Seto et al., 1988). The physiological role of this enzyme is not known.

In the present study, we have investigated the guanosine kinase pathway. First it appears that the pathway is inefficient. Exogenous guanosine can be used when only GMP is needed, but 
Table 6. Genetic mapping of the gsk gene

Bacteriophage Pl mediated transductions were conducted as described in Methods. The Tet ${ }^{\mathrm{R}}$ marker of strain Sø1726 is the $z b b-2419:: \operatorname{Tn} 10$ allele (Table 1).

\begin{tabular}{|c|c|c|c|c|}
\hline $\begin{array}{l}\text { Recipient } \\
\text { strain }\end{array}$ & $\begin{array}{l}\text { Donor } \\
\text { strain }\end{array}$ & $\begin{array}{c}\text { Selected } \\
\text { marker }\end{array}$ & $\begin{array}{l}\text { Scored } \\
\text { markers }\end{array}$ & No. \\
\hline \multirow[t]{2}{*}{ HO55 (proC purE apt) } & $\mathrm{N} 43($ acr $A)$ & $\mathrm{pro}^{+}$ & $\begin{array}{l}\text { acr } A^{+} \text {apt } \\
\text { acr } A \text { apt } \\
\text { acr } A \text { apt } \\
\text { acr } A^{+} \text {apt }\end{array}$ & $\begin{array}{r}473 \\
13\end{array}$ \\
\hline & & pur ${ }^{+}$ & $\begin{array}{l}a c r A^{+} \text {apt } \\
a c r A^{+} a p t^{+} \\
a c r A \quad a p t^{+}\end{array}$ & $\begin{array}{r}199 \\
6 \\
1\end{array}$ \\
\hline $\mathrm{S} \varnothing 1726\left(\mathrm{Tet}^{\mathrm{R}} a d k\right)$ & $\mathrm{S} \varnothing 445(g s k-l)$ & $a d k^{+}$ & $\begin{array}{ll}g s k^{+} & \mathrm{Tet}^{\mathrm{R}} \\
g s k & \mathrm{Tet}^{\mathrm{R}} \\
g s k & \mathrm{Tet}^{\mathrm{S}} \\
g s k^{+} & \mathrm{Tet}^{\mathrm{S}}\end{array}$ & $\begin{array}{r}64 \\
137 \\
182 \\
19\end{array}$ \\
\hline $\mathrm{S} \varnothing 1726\left(\right.$ Tet $\left.^{\mathrm{R}} a d k\right)$ & Sø446 (apt) & $a d k^{+}$ & $\begin{array}{ll}\text { apt } & \mathrm{Tet}^{\mathrm{R}} \\
\text { apt } & \mathrm{Tet}^{\mathrm{R}} \\
\text { apt } & \mathrm{Tet}^{\mathrm{S}} \\
\text { apt } & \mathrm{Tet}^{\mathrm{S}}\end{array}$ & $\begin{array}{l}29 \\
77 \\
22 \\
78\end{array}$ \\
\hline
\end{tabular}

cannot be used when there is an additional demand to supply AMP. The limiting process apparently is not guanosine transport. Rather the formation of GMP from guanosine most likely is growth limiting in purE deoD strains, but this is not the case in guaA deoD strains. The difference between the two strains is that ATP is abundant in the guaA strain. In contrast to the purE strain, the de novo synthesis of AMP is not impaired in the guaA strain. ATP is not only required by guanosine kinase for activity, but high levels stimulate the enzyme. As a consequence, only small amounts of GMP are formed in the purE deoD strain and conversion to AMP does not occur via the GMP reductase pathway (Fig. 1), because the induction of this conversion pathway requires a high level of guanine nucleotides. This appears to explain why purE deoD strains do not utilize guanosine as the sole purine source. Another consideration is that ATP stimulates the synthesis of GMP and also inhibits the conversion of GMP to AMP. Thus, the increased synthesis of GMP in guaA deoD strains solely furnishes the cell's demand for guanine nucleotides.

The fact that $E$. coli possesses guanosine kinase activity probably reflects that guanosine salvage occurs and that this only can be a supplement to the overall nucleotide synthesis. All the guanosine-utilizing mutants isolated showed altered guanosine kinase activity (Table 4). Preliminary kinetic investigations of guanosine kinase in cell-free extracts from the gsk mutants indicate that the kinetic properties are altered, the apparent $K_{\mathrm{m}}$ for guanosine being lowered. Besides the gsk mutation we identified mutations that caused deficiencies in one of the early enzymes of the purine biosynthetic pathway, catalysing the steps before the purE-encoded reaction. If we consider the synthesis of phosphoribosylpyrophosphate as an early step in purine biosynthesis (Fig. 1), strain Sø1172 belongs to this group of double mutants (Table 4). An exception to this is strain HO3. In this mutant, we found no evidence for additional mutations. However, the growth of this strain on guanosine is reduced compared to the double mutants (Table 3). The additional defects in the de novo purine pathway are apparently advantageous.

When purE strains are starved for purines they accumulate AIR. Because this compound in fact is a purine analogue, it appears to inhibit guanosine metabolism. The guanosine-utilizing mutants isolated by Livshits \& Sukhodolets $(1973 b)$ were obtained in a pur $D$ deo $D$ genetic background. This proves that accumulation of AIR during purine starvation is not a prerequisite for the isolation of guanosine-utilizing mutants. Rather, AIR further stresses the cells and gives rise to mutants synthesizing more efficient enzymes. As can be seen in Table 3 the guanosine-utilizing mutants $\mathrm{HO} 1, \mathrm{HO} 4$ and $\mathrm{HO} 9$ (with additional defects in a pur gene) also grew better on guanine than did $\mathrm{HO} 3$, which harbours a gsk mutation alone. This might indicate 
that the GMP reductase pathway is inhibited by AIR which accumulates in purE strains when starved for purines.

B. Bachmann, K. Hammer, H. Nakamura and B. Mygind are acknowledged for generously providing bacterial strains and J. Steno Christensen for excellent technical assistance.

\section{REFERENCES}

BachmanN, B. (1972). Pedigrees of some mutant strains of Escherichia coli K-12. Bacteriological Reviews 36, 525-557.

BACHMANN, B. (1983). Linkage map of Escherichia coli K-12, edition 7. Microbiological Reviews 47, 1-56.

Bratton, A. C. \& Marshall, E. K. (1939). A new coupling component for sulfanilamide determination. Journal of Biological Chemistry 128, 537-550.

Chumley, F., Menzel, R. \& Roth, J. R. (1979). Hfr formation directed by Tn10. Genetics 91, 639-655.

Clark, D. J. \& MaAløE, O. (1967). DNA replication and the division cycle in Escherichia coli. Journal of Molecular Biology 23, 99-112.

FINK, K. \& NygaARD, P. (1978). Pyrimidine metabolism in microplasmodia of Physarum polycephalum. European Journal of Biochemistry 89, 417-424.

Gots, J. S., Benson, C. E., Jochimsen, B. U. \& Koduri, R. K. (1977). Microbial models and regulatory elements in the control of purine metabolism. In Purine and Pyrimidine Metabolism (CIBA Foundation Symposium vol. 8), pp. 23-41. Amsterdam: Elsevier/North Holland.

Hammer-Jespersen, K. \& Munch-Petersen, A. (1973). Mutants of Escherichia coli unable to metabolize cytidine: isolation and characterization. Molecular and General Genetics 126, 177-186.

Hansen, S. E. W., Jensen, N. \& Munch-Petersen, A. (1987). Studies on the sequence and structure of the Escherichia coli K-12 nupG gene encoding a nucleoside-transport system. European Journal of Biochemistry 168, 385-391.

Hoffmeyer, J. \& NeuHARd, J. (1971). Metabolism of exogenous purine bases and nucleosides by Salmonella typhimurium. Journal of Bacteriology 106, 14-24.

Houlberg, U., Hove-Jensen, B., Jochimsen, B. \& NyGAARD, P. (1983). Identification of the enzymatic reactions encoded by the purG and purI genes of Escherichia coli. Journal of Bacteriology 154, 14851488.

Hove-Jensen, B. (1983). Chromosomal location of the gene encoding phosphoribosylpyrophosphate synthetase in Escherichia coli. Journal of Bacteriology 154, 177-184.

HoVE-JENSEN, B. (1985). Cloning and characterization of the prs gene encoding phosphoribosylpyrophosphate synthetase of Escherichia coli. Molecular and General Genetics 201, 269-276.

Hove-Jensen, B. \& NygaARd, P. (1982). Phosphoribosylpyrophosphate synthetase of Escherichia coli. Identification of a mutant enzyme. European Journal of Biochemistry 126, 327-332.

Hove-Jensen, B., Harlow, K. W., King, C. J. \& Switzer, R. L. (1986). Phosphoribosylpyrophosphate synthetase of Escherichia coli. Properties of the purified enzyme and primary structure of the prs gene. Journal of Biological Chemistry 261, 6765-6771.
Jensen, K. F. (1978). Purine nucleoside phosphorylases in bacteria. Thesis, University of Copenhagen.

Jensen, K. F., Houlberg, U. \& NygaARd, P. (1979). Thin-layer chromatographic methods to isolate ${ }^{32}$ P-labeled 5-phosphoribosyl- $\alpha$-1-pyrophosphate (PRPP): determination of cellular PRPP pools and assay of PRPP synthetase activity. Analytical Biochemistry 98, 254-263.

JoCHIMSEN, B. U. (1979). Purine metabolism in bacteria. Regulation of enzymes involved in auxiliary pathways. Thesis, University of Copenhagen.

JoChIMSEN, B., NygAaRd, P. \& VestergaARD, T. (1975). Location on the chromosome of Escherichia coli of genes governing purine metabolism. Molecular and General Genetics 143, 85-91.

Jochimsen, B. U., Hove-Jensen, B., Garber, B. B. \& GoTs, J. S. (1985). Characterization of a Salmonella typhimurium mutant defective in phosphoribosylpyrophosphate synthetase. Journal of General Microbiology 131, 245-252.

KARLSTRÖM, O. (1970). Failure of Escherichia coli B to incorporate added deoxycytidine, deoxyadenosine and deoxyguanosine into DNA. European Journal of Biochemistry 17, 68-71.

LENNOX, E. S. (1955). Transduction of linked genetic characters of the host by bacteriophage Pl. Virology 1, 190-206.

LIVsHITs, V. A. (1976). Effect of 2,6-diaminopurine resistant mutations on the utilization of adenine and adenosine by adenine-requiring Escherichia coli $\mathrm{K}-12$ strains. Genetika 12, 180-182.

Livshits, V. A. \& Sukhodolets, V. V. (1973a). Mutants of Escherichia coli $\mathrm{K}-12$ defective in purine nucleoside phosphorylase and in de novo synthesis of purine nucleotides. Genetika 9, 66-75.

LIVSHITS, V. A. \& SUKHODOLETS, V. V. (1973b). On the role of adenine nucleotides in the regulation of purine ribonucleoside utilization by mutants of Escherichia coli defective in purine nucleoside phosphorylase. Genetika 9, 102-111.

Munch-Petersen, A. \& Mygind, B. (1976). Nucleoside transport systems in Escherichia coli $\mathrm{K} 12$ : specificity and regulation. Journal of Cellular Physio$\log y$ 89, 551-559.

Munch-Petersen, A. \& Mygind, B. (1983). Transport of nucleic acid precursors. In Metabolism of Nucleotides, Nucleosides and Nucleobases in Microorganisms, pp. 259-305. Edited by A. Munch-Petersen. London: Academic Press.

Nakamura, H., Tojo, T. \& Greenberg, J. (1975). Interaction of the expression of two membrane genes, acr $A$ and plsA, in Escherichia coli K-12. Journal of Bacteriology 122, 874-879.

NeuHaRd, J. \& NyGAaRd, P. (1987). Biosynthesis and conversion of nucleotides, purines and pyrimidines. In Escherichia coli and Salmonella typhimurium. 
Cellular and Molecular Biology, pp. 445-473. Edited by F. C. Neidhardt, J. L. Ingraham, K. B. Low, B. Magasanik, M. Schaechter \& H. E. Umbarger. Washington: American Society for Microbiology.

Neuhard, J., Randerath, E. \& Randerath, K. (1965). Ion-exchange thin-layer chromatography. XIII. Resolution of complex nucleoside triphosphate mixtures. Analytical Biochemistry 13, 211-222.

Newell, P. C. \& TuCKER, R. G. (1968). Biosynthesis of the pyrimidine moiety of thiamine. A new route of pyrimidine biosynthesis involving purine intermediates. Biochemical Journal 106, 279-287.

NyGAARD, P. (1983). Utilization of preformed purine bases and nucleosides. In Metabolism of Nucleotides, Nucleosides and Nucleobases in Microorganisms, pp.
27-93. Edited by A. Munch-Petersen. London: Academic Press.

Ray, T. K., Cronan, R. D., JR, Mavis, R. D. \& VAGELOS, P. R. (1970). The specific acylation of glycero-3-phosphate to monoacyl-glycero-3-phosphate in Escherichia coli. Evidence for a single enzyme conferring this specificity. Journal of Biological Chemistry 245, 6442-6448.

Seto, D., Bhatnagar, S. K. \& Bessman, M. J. (1988). The purification and properties of deoxyguanosine triphosphate triphosphohydrolase from Escherichia coli. Journal of Biological Chemistry 263, 1494-1499.

SMITH, R. W. \& SADLER, J. R. (1971). The nature of lactose operator constitutive mutations. Journal of Molecular Biology 59, 273-305. 